\title{
The Relationship Between Activity and Cell-wall Permeability in Dried Baker's Yeast
}

\author{
BY L. I. K. EBBUTT \\ The Distillers Co., Ltd., Glenochil Research Station, Menstrie, Clackmannanshire
}

(Received 21 October 1960)

\begin{abstract}
SUMMARY
A close relationship has been found between the baking activity of dried yeast and the yeast cell volume after reconstitution; other things being equal, the cell volume is in turn dependent upon the permeability of the cell wall. It appears that the total observed loss of activity occasioned by drying yeast may be attributed to increased cell-wall permeability.
\end{abstract}

\section{INTRODUCTION}

In the production of dried baker's yeast a strain of Saccharomyces cerevisiae is used and the moisture content is decreased from about 70\% to 7-8\% by a drying process which may be one of several alternatives. Drum drying, in which the pressed yeast is placed in a revolving drum and dried in a current of hot air, is one method used. The product shows markedly improved storage properties. Whereas pressed yeast loses much of its baking activity after 1 week at room temperature, dried yeast may be stored for several months without appreciable deterioration. When required for use, dried yeast is simply added to the desired quantity of water and a suspension of rehydrated cells is obtained after a few minutes; this process is commonly referred to as reconstitution. Even the most favourable drying conditions, however, cannot produce a dried yeast which retains all the activity which it originally possessed in the pressed state; a greater or lesser proportion of the original activity is lost on drying, the extent of the loss depending on the strain of yeast used, the drying conditions and the method by which the yeast was propagated. As a general rule, the higher the initial activity the greater the loss suffered on drying.

It has been known for some time that dried yeasts become permeable to small molecules and ions, as shown by the work of Meyerhof \& Kaplan (1951), Herrera, Peterson, Cooper \& Peppler (1956), and Rothstein, Jennings, Dennis \& Bruce (1959). While this is suggestive of a connexion between cell permeability and activity, the extent of the relationship has not been investigated. It has indeed been suggested that a decrease in permeability occurs on drying, resulting in a slower release of enzymes to the medium (Proskuryakov \& Operysheva, 1956). It is the intention in this paper to show that the relationship between dried-yeast activity and cell-wall permeability is so close as to suggest that the latter is the main determining factor in dried-yeast performance; a rapid method for assessing the over-all permeability of the yeast cell wall is also given.

Throughout the work described here, cell-volume measurements were used as an indication of the over-all permeability of the cell wall. In order to appreciate the validity of this assumption it is necessary to consider the osmotic equilibrium of the 
yeast cell. The normal healthy yeast cell consists of a mass of protoplasm enclosed by a structural cell wall together with the plasma membrane. In this respect it resembles most plant cells, although in plants the cell wall is relatively rigid so that when the cell is plasmolysed the membrane detaches itself from the cell wall and shrinks along with the cytoplasm, leaving the cell wall unaltered in size and shape. It has been shown in this laboratory, however, that a linear relationship exists between cell volume and external osmotic pressure up to 10 atmospheres, i.e. there is Hookean behaviour within this range; beyond this point the relationship is nonlinear, the cell volume decrease for a given osmotic pressure being less than expected. Nevertheless, the yeast cell volume progressively decreases with increasing osmotic pressure up to at least 25 atmospheres. It is thus assumed that the cell wall is flexible, and that true plasmolysis does not occur, up to an external osmotic pressure of at least 10 atmospheres. Within this range the osmotic pressure inside the cell must always be greater than that outside, equilibrium being established when the external osmotic pressure plus the tension within the cell wall balances the internal osmotic pressure. For any yeast suspended in a given liquid the cell volume will thus be a function of the internal osmotic pressure, this being the integrated effect of all the soluble cell components within the plasma membrane. If the cell now becomes permeable to a certain range of molecular species these will no longer contribute to the internal osmotic pressure and the cell will immediately react and restore equilibrium by assuming a smaller volume with a consequent decrease in cell-wall tension; this change will take place before the molecular species concerned has diffused from the cell. The wider the range of molecular species to which the cytoplasmic membrane becomes permeable, the greater will be the diminution in cell volume. Cell volume may therefore be taken as a measure of the over-all permeability of the membrane.

It was shown by Eirich, Bunzl \& Margaretha (1936) that the Einstein equation relating the viscosity of a suspension to the volume fraction of the particles was valid for yeast cells in dilute suspension, i.e. the viscosity is independent of the size distribution. For more concentrated cell suspensions the Einstein equation does not apply, but other workers have produced equations which are claimed to be valid e.g. Mooney (1951), Orr \& Blocker (1955), Ting \& Luebbers (1957). These equations all differ to a greater or lesser degree but they all verify the fact that the viscosity is a function of volume fraction only.

It was found in this laboratory that no electroviscous effect was apparent under the conditions used, possibly due to the high cell concentration or to the fact that when commercial baker's yeast is suspended in water a number of ionic species are found to be leached from the cells in small concentrations; the ionic strength is probably sufficient to neutralize the electroviscous effect. A calibration curve relating viscosity and cell volume fraction could then be prepared from which the latter could be directly determined. The average dry matter content $(D M)$ of pressed yeast is $27 \%$ so this volume was adopted as the standard to which estimations were adjusted, enabling valid comparisons to be made.

The cell volume fraction at $27 \% D M\left(\phi_{27}\right)$ was obtained from the following relationship

$$
\phi_{27}=\frac{V s \phi_{s}}{\left(V s-E^{\prime}\right)+W(D M / 27-1)},
$$


where: $V s=$ vol. of yeast suspension on which measurements were taken; $\phi_{s}=$ cell volume fraction of suspension; $E^{\prime}=$ vol. of water added to prepare suspension; $W=$ wt. of yeast sample used; $D M=$ dry matter content of yeast sample.

Once the values of $\phi_{27}$ for two different yeast samples, or for the same sample before and after a given treatment, have been determined, the ratio between the values will correspond to the ratio between the mean cell sizes, assuming that the dry matter/cell remains constant.

This method for the determination of cell volumes was evaluated and chosen because of the need for greater precision than may be obtained with the centrifuged cell-volume technique; the accuracy of the viscosity measurement was such that changes in cell volume fraction of $\pm 0.05 \%$ could be detected. Moreover, an instantaneous reading is obtained and a continuous record of any progressive change may be made.

\section{METHODS}

Measurement of viscosity. Viscosity was measured with a 'Poisemeter' electric viscometer manufactured by Messrs Dobbie McInnes Ltd. (Glasgow). The instrument consists essentially of a constant speed electric motor driving a drag member within the fluid to be measured. Changes in viscous drag cause changes in the current flowing in the motor circuits and these changes are indicated on a scale calibrated in angular degrees. The indication obtained varies approximately as the logarithm of the dynamic viscosity of the fluid being measured. Good reproducibility can be obtained. Errors due to variations in mains voltage or frequency are compensated within the instrument.

Calibration of viscometer. In order to obtain a calibration curve relating scale reading or viscosity to cell-volume fraction it was necessary to determine the external water content of a sample of pressed yeast, since the distribution of water in this material may be such that about $25 \%$ of the total is outside the cells (White, 1954). This determination was done by the inulin method (Conway \& Downey, $1950 a$ ). It was known from previous experience that it was desirable to operate within the range of cell volume fractions of $0.50-0.57$; above this range the suspension is too viscous to be readily handled, while with more dilute suspensions the sensitivity of viscosity to changes in cell volume diminishes rapidly. Yeast (450 g.) was made into suspension with sufficient water $(210 \mathrm{ml}$.) to give a cell-volume fraction of approximately $\mathbf{0 . 5 7}$. Distilled water was added in $5 \mathrm{ml}$. amounts and the viscosity read after each addition. All measurements were carried out at $20^{\circ}$. The external water content of the yeast used was found to be $14.3 \%(v / w)$, from this and the volume of the suspension the volume fraction could be calculated for each dilution by the relationship $\phi_{s}=1-\left(E+E^{\prime}\right) / V_{s}$, where $E=$ vol. of external water in $450 \mathrm{~g}$. pressed yeast, $\boldsymbol{E}^{\prime}=$ total vol. of water added at each dilution, and $\phi_{s}=$ volume fraction of the suspension.

Preparation of samples. For an accurate viscometer reading about $600 \mathrm{ml}$. of yeast suspension was required; this was provided by the suspension of $450 \mathrm{~g}$. pressed yeast in $200 \mathrm{ml}$. water or $200 \mathrm{~g}$. dried yeast in $500 \mathrm{ml}$. water. These usual quantities were, however, frequently varied for special trials. All samples were brought to $20^{\circ}$ before measurement.

Drying technique. The experiments described in this paper were carried out with 
a yeast strain of high activity which is not normally used for dried yeast production (standard DCL baker's yeast). This enabled a wide range of activities to be studied since this material was found to give very variable results on drying. Pressed yeast (1000 g.) was forced through a die by means of a hydraulic ram to yield a mass of long, vermicelli-like strands of extruded yeast (1/20 in. diameter), and was then transferred to a drying drum, 16 in. in length and 9 in. diameter, constructed from sheet steel. The drum was rotated at $24 \mathrm{rev} . / \mathrm{min}$. and dry air at $50^{\circ}$ passed through at a flow rate of $5 \mathrm{foot}^{3} / \mathrm{min}$. The interior of the drum was fitted with three 'flights', each 16 in. $\times 1 \frac{1}{2}$ in., to lift the yeast to near the top of the drum and then allow it to fall through the air stream. During drying the long strands of yeast were rapidly broken down to small pellets. Drying was continued until the moisture content had fallen to $8 \%$, this taking usually about $16 \mathrm{hr}$.

Examination of the permeability of cells to specific substances. Pressed yeast (450 g.) was suspended in $180 \mathrm{ml}$. water and adjusted to $\mathrm{pH} \mathrm{5.0.} \mathrm{The} \mathrm{temperature}$ was brought to $20^{\circ}$ and the viscosity adjusted to a particular reference point on the viscometer scale by the further addition of water; $600 \mathrm{ml}$. of this suspension were then measured into a clean dry vessel. The cell-volume fraction of this suspension was then 0.599 , i.e. $335 \mathrm{ml}$. cells and $265 \mathrm{ml}$. water. Ten ml. of a solution containing such a weight of the substance under examination as to make $275 \mathrm{ml}$. of $\mathbf{0 . 2 5}$ osmolar solution were pipetted into the suspension and the reading observed after $2 \mathrm{~min}$. and at such intervals thereafter as was considered necessary. The relative cell volume (RCV) i.e. cell volume after addition/cell volume before addition was then obtained from a previously prepared graph. When the substance under examination did not pass through the cell wall it would, of course, exert an osmotic effect and the observed viscosity would be much lower than that calculated for the addition of $10 \mathrm{ml}$. water alone; moreover, the reading would be constant. For a substance which passed through the cell wall and took a measurable time to do so, the viscosity would show the same initial decrease, but as the substance slowly diffused into the cell the cell volume and viscosity would increase until diffusion equilibrium was attained, when the internal and external concentrations were equal and the RCV had risen to 1.0. Finally, a substance which immediately entered the cell would exert no osmotic action and the relative cell volume would remain at $1 \cdot 0$, the viscosity of the solution decreasing only by the addition of the $10 \mathrm{ml}$. liquid. A similar procedure was used for dried yeasts.

Determination of yeast activity. For this test the standard fermentometer apparatus as described by Burrows \& Harrison (1959) was used. Yeast (1.5 g.) was suspended in about $100 \mathrm{ml}$. water at $37.5^{\circ}$ and allowed to stand for $15 \mathrm{~min}$. at about $18^{\circ}$; $62.5 \mathrm{ml}$. of $10.8 \%(\mathrm{w} / \mathrm{v})$ sodium chloride were then added to the suspension and the volume made up to $250 \mathrm{ml}$. Of this suspension $15 \mathrm{ml}$. were pipetted into a fermentometer bottle and left for 15-20 min. in the fermentometer bath; $20 \mathrm{~g}$. flour was then added and mixed thoroughly. Thirteen minutes after the addition of flour the system was closed to the atmosphere and the volume of gas evolved after $3 \mathrm{hr}$. recorded. The observed gas volume was corrected to $20^{\circ}$ and $760 \mathrm{~mm}$. $\mathrm{Hg}$. pressure and the yeast activity expressed as $\mathrm{ml}$. gas evolved/g. dry matter.

Determination of yeast dry matter. An accurately weighed sample of about $1 \mathrm{~g}$. was dried at $105^{\circ}$ for $6 \mathrm{hr}$. in a laboratory oven and re-weighed after cooling in a desiccator. The dry matter was calculated from the loss in weight. 


\section{RESULTS}

\section{Comparison between pressed and dried yeasts}

Cell volume. A microscopic examination of the cells of pressed yeast before drying and of the cells as reconstituted after drying revealed no morphological difference other than the fact that the cells after drying appeared smaller. This observation was confirmed by measurement of the cell-volume fraction. This was found to be 0.811 for a sample of pressed yeast; after drying to $8 \%$ moisture and reconstitution, a $\phi_{27}$ value of 0.526 was obtained. Hence the mean cell volume after drying was only $65 \%$ of that before drying.

Effect of sodium chloride. Two reasons for the decrease in cell volume on drying seemed possible: either an increase in the permeability of the cell wall or an alteration of the mechanical properties of the wall may have occurred. To distinguish between these possibilities it was necessary to examine directly the permeability of dried yeast. It is well known that the inner region of the yeast cell wall is impermeable to sodium chloride under normal circumstances although the compound will permeate throughout the outer region (cf. Conway \& Downey, 1950b; Malm, 1947; Kotyk \& Kleinzeller, 1958). This was verified by the addition of sodium chloride to a sample of standard yeast cream to make a $0.125 \mathrm{M}$-solution in the external water. The relative cell volumes obtained were $0.9543,0.9540$ and 0.9530 for three different yeast samples, the viscosity remaining constant for periods up to at least $24 \mathrm{hr}$. This experiment was repeated on two samples of dried yeast, reconstituted at $37.5^{\circ}$, from different laboratory dryings. With both samples it was found that the RCV remained at $1 \cdot 0$, apparently indicating that the sodium chloride passed immediately through the cell wall. It could still be argued, however, that the mechanical properties of the cell wall had been altered by drying to such an extent that it was capable of withstanding the osmotic forces. To test this possibility, the extent to which the sodium chloride had penetrated the cell was estimated directly by titration of the filtrate from a cell suspension containing a known weight of sodium chloride. From a knowledge of the cell-volume fraction it was readily calculated that the salt had penetrated through $60 \%$ of the cell volume, assuming that only simple diffusion was involved.

Permeation by other substances. The effect of a number of other substances on reconstituted dried yeast was examined. These included: urea, thiourea, malonamide, acetamide, glucose, sucrose, hexamethylenetetramine, peptone. Each of these substances was found to pass directly through the cell wall, whereas in the case of pressed yeast they either did not penetrate the wall or passed through at a relatively slow and measurable rate. It was of interest to note that the cell wall of the strain of pressed yeast used was completely impermeable to hexamethylenetetramine, even after prolonged exposure; Ørskov (1945) found that this substance diffused slowly through the cell wall of a different strain. This indicates that different strains of yeast can show different permeability relationships.

\section{Reconstitution of dried yeast at different temperatures}

The activity of dried yeast is greatly influenced by the temperature of reconstitution (Peppler \& Rudert, 1953), 37.5 $5^{\circ}$ being considered the optimum by many authorities, although this value is not critical within a few degrees. Two identical 
samples of dried yeast were reconstituted, one at $37 \cdot 5^{\circ}$ and the other at $8^{\circ}$. The values of $\phi_{27}$ were found to be $\mathbf{0 . 5 8 2}$ and $\mathbf{0 . 5 1 3}$, respectively, as compared with 0.801 for the same yeast before drying. The permeability to urea of the original yeast and of the two reconstituted samples was also examined. It was found that diffusion equilibrium was reached in $9 \mathrm{hr}$. with the pressed yeast, $1.5 \mathrm{hr}$. with the sample reconstituted at $37 \cdot 5^{\circ}$, while diffusion equilibrium was instantaneous with the final sample reconstituted at $8^{\circ}$.

\section{Autofermentation}

It was found that the reconstitution of dried yeast in the quantity and concentration required for viscosity determination gave rise to vigorous autofermentation which persisted for 1 to $\mathbf{2} \mathrm{hr}$. Moreover, although no measurements of gas evolution were taken, it was obvious that the more active the yeast, the more vigorous the fermentation. Viscometer measurements were normally postponed until gassing had ceased. The substrate for this autofermentation is not known, but no fermentable carbohydrate was detected in the filtrate from a freshly reconstituted dried yeast. It appears that the increased permeability of the cell wall creates a certain amount of disorder within the cell and in the cell-wall region, whereby enzymes are allowed to come into contact with substrates which would not normally be available in the intact healthy cell. The view held is that a 'perfect' dried yeast would show no autofermentation; slightly damaged yeasts, however, exhibit vigorous autofermentation, indicating that there is still a good capacity for fermentation although the disarrangement of the cell is sufficient to bring normally separated enzymes and substrates into close proximity. As the amount of damage becomes more extensive, the over-all fermentative capability decreases through the loss and dilution of essential co-enzymes etc., and this effect more than counterbalances the increased substrate availability. By the use of iodoacetic acid as an inhibitor of the autofermentation it was shown that a decrease in the permeability of the cell wall took place during this period. Dried yeast was reconstituted at $37 \cdot 5^{\circ}$ in water containing $0.2 \%(w / v)$ iodoacetic acid; the $\phi_{27}$ value was 0.571 . A further sample of the same yeast was reconstituted in the normal manner and $0.2 \%(w / v)$ iodoacetic acid added to this suspension after autofermentation had ceased; the $\phi_{27}$ value was then $0 \cdot 637$. The two samples were examined for permeability to urea in the usual way. It was found that the cell permeability corresponded to the difference in cell volumes, diffusion equilibrium taking about $1 \mathrm{hr}$. for the sample to which iodoacetic acid was added immediately, and 4 to $5 \mathrm{hr}$. for the other.

\section{Relationship between cell volume and activity}

The determination of the cell volume and permeability of a number of dried yeast samples showed that they did not all behave in the manner previously described, i.e. were fully permeable to all substances for which measurement was possible. This was found to apply only to yeasts of very poor quality. Yeast samples of higher activity were examined as they became available and it was found that they exhibited a variety of permeability effects according to their activity. Very active samples were completely impermeable to sodium chloride but permitted the passage of urea fairly rapidly; other samples of lesser activity were almost instantaneously permeable to urea and allowed sodium chloride to diffuse at a measurable 
rate. It had been hoped to find some substance which could be used in a standard permeability test and which would show a measurable but variable permeation rate with all yeast samples, i.e. never becoming zero or infinite with any sample. It became apparent, however, that such an ideal could not be attained and it was at this stage that the cell volume was adopted as a measure of the over-all permeability of the cell.

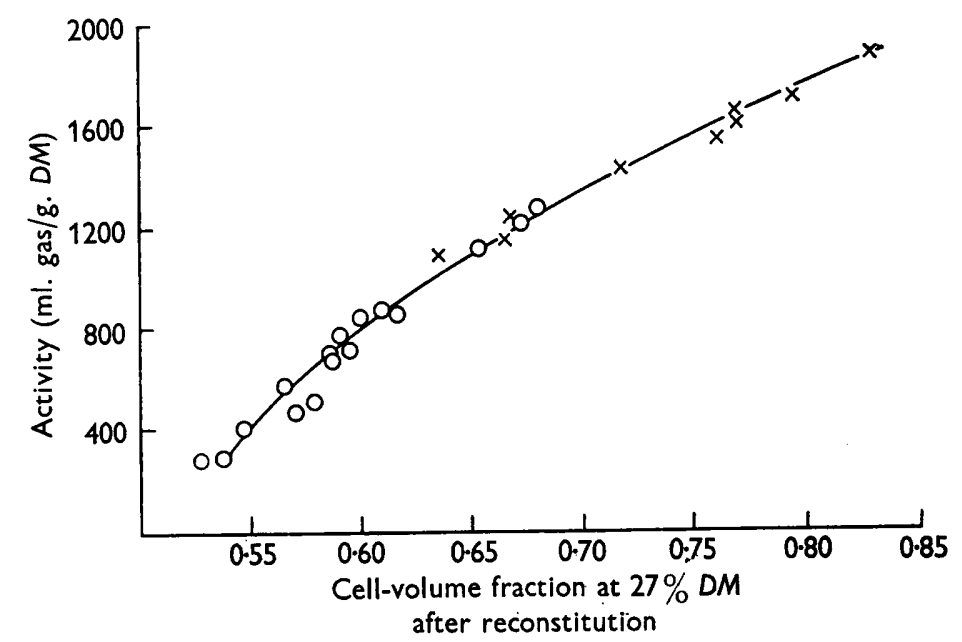

Fig. 1. Relationship between activity of pressed yeast and cell-volume fraction at $27 \%$ dry matter $(D M)$ after reconstitution. $O$, Fully dried samples; $x$, samples removed at intervals during drying.

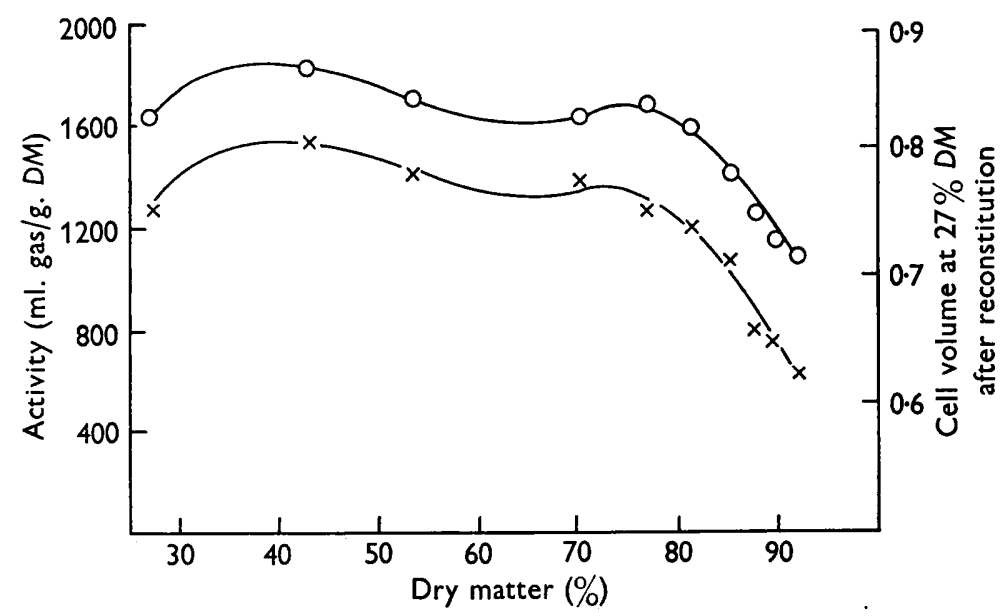

Fig. 2. Relationship between activity, cell-volume fraction and dry matter during the course of drying. $O$, yeast activity; $x$, cell-volume fraction at $27 \%$ dry matter $(D M)$ after reconstitution.

A number of laboratory dryings of different batches of yeast were carried out and the dried products examined for cell volume and activity. The results of this series are given in Fig. 1 (circled points) where it will be seen that there is a very close relationship between these variables. As an extension of this, the cell volume and activity were measured at intervals during the drying process in one case (Fig. 2). 
The cell volume curve was found to be an exact duplicate of the activity curve. When these results were transferred to Fig. 1 (crosses) they formed a smooth extension to the curve already obtained.

To prove that the diminution in cell volume and the increased permeability of the cell were not merely incidental consequences of the loss in activity, a number of identical samples of cream prepared from pressed yeast were incubated for various times at $45^{\circ}$ and the cell-volume fraction then measured after cooling to $20^{\circ}$. A portion of each suspension was filtered after incubation and the activity and dry matter of the pressed samples determined. It was shown thereby that the activity of yeast could be almost completely destroyed without the cell volume being significantly affected (Fig. 3).

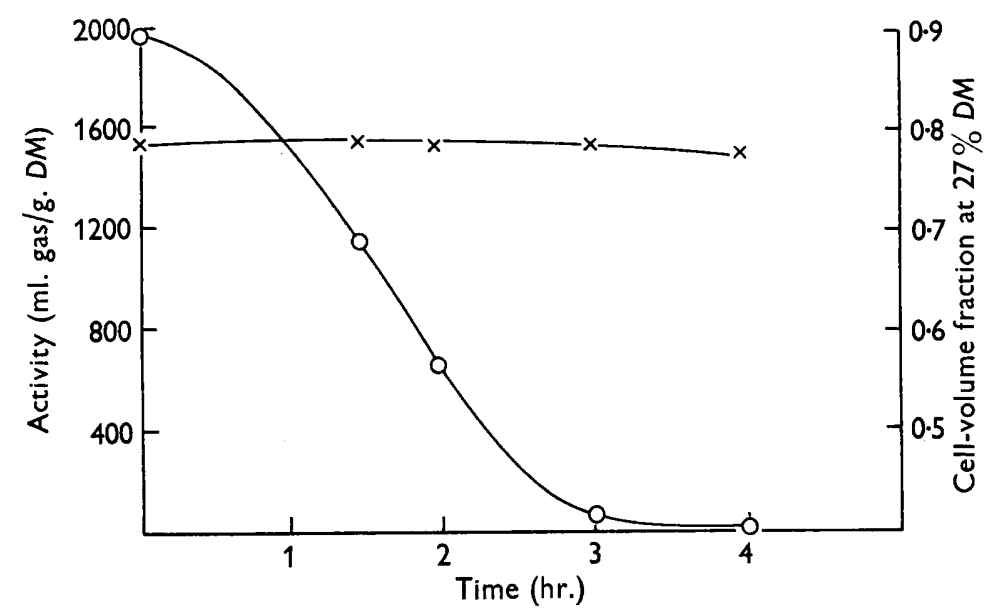

Fig. 3. Effect of incubation of yeast cream at $45^{\circ}$. $O$, yeast activity; $x$, cell volume fraction at $27 \%$ dry matter $(D M)$.

Throughout the investigations mentioned in this paper, the $\mathrm{pH}$ value of reconstituted dried yeast suspensions was routinely measured. There was a fairly good correlation between $\mathrm{pH}$ value and activity; suspensions of poor dried yeasts had

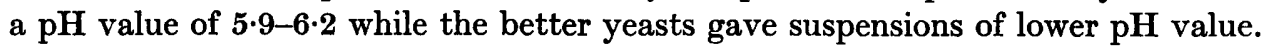
This observation is a further reflection of the increased permeability of poor dried yeasts, since the internal $\mathrm{pH}$ value of the strain used is about $6 \cdot 0-6 \cdot 2$.

\section{DISCUSSION}

The results presented here serve to illustrate the fact that the permeability of the cell wall is of primary importance in dried yeast research. From the evidence collected it does not appear that any other hypothesis need be invoked to account for the disparity between the activity before and after drying. The correlation between activity and cell volume is sufficiently good to indicate that the former is a function principally of the latter. It was originally thought that heat inactivation of enzymes might play a part, but it seems probable that such an effect is insignificant as compared with the activity loss brought about by increased permeability of cell wall. The view now held is that during drying, no matter how low the moisture content may be diminished, there is no damage to the fermentation system of the 
yeast provided that the drying temperature is not excessively high. From approximately $80 \%$ dry matter onwards, however, there is a progressive disarrangement of the cytoplasmic membrane. The damage only becomes apparent when the yeast is resuspended in water and loss of essential components occurs.

The work of Herrera et al. (1956) is of particular interest in relation to the results presented here. In studying the differences in activity caused by reconstituting dried yeast at various temperatures it was found that $75 \%$ of the cell diphosphopyridine nucleotide (DPN) was extracted at $4-5^{\circ}$, as compared with $15 \%$ at $43^{\circ}$. These authors suggested that the difference might be accounted for in terms of the rate of rehydration of the cytoplasmic membrane, this process being slow at a low temperature and comparatively fast at the higher temperature of $43^{\circ}$. It is possible that the increase in cell volume reported here as occurring during the autofermentation period was the final stage of such a process. It is to be hoped that future work may yield more definite information about the composition and physical state of the cytoplasmic membrane; this knowledge would be of great value in solving problems associated with drying yeast and other micro-organisms.

\section{REFERENCES}

Burrows, S. \& Harrison, J. S. (1959). Routine method for determination of the activity of baker's yeast. $J$. Inst. Brewing, 65, 39.

Conway, E. J. \& Downey, M. (1950a). An outer metabolic region of the yeast cell. Biochem. J. 47, 347.

Conway, E. J. \& Downey, M. (1950b). pH values of the yeast cell. Biochem. J. 47, 355.

Eirich, F., Bunzl, M. \& Margaretha, M. (1936). The viscosity of suspensions of spheres. Kolloid-Z. 74, 275.

Herrera, T., Peterson, W. H., Cooper, E. J. \& Peppler, H. J. (1956). Loss of cell constituents on reconstitution of active dry yeast. Arch. Biochem. Biophys. 63, 131.

Kotyk, A. \& Kueinzeller, A. (1958). Movement of sodium and cell volume changes in a sodium-rich yeast. J. gen. Microbiol. 20, 197.

Malm, M. (1947). Permeability of yeast cells and the plasma changes caused by permeable materials. Ark. Kemi. Min. Geol. 25 A, 187.

MeYerhoF, O. \& KaPLAN, A. (1951). The speed-controlling reactions in fermentation of quickly dried yeast. Arch. Biochem. Biophys. 33, 282.

MoONEy, M. (1951). The viscosity of a concentrated suspension of spherical particles. J. Colloid Sci. 6, 162.

OrR, Jun., C. \& Blocker, H. G. (1955). The viscosity of suspensions of spheres. J. Colloid Sci. 10, 24.

ØrSkov, S. L. (1945). Investigations on the permeability of yeast cells. Acta path. microbiol. scand. 22, 523.

Peppler, H. J. \& Rudert, F. J. (1953). Comparative evaluation of some methods for estimation of the quality of active dry yeast. Cereal Chem. 30, 146.

Proskuryakov, N. I. \& Operysheva, E. F. (1956). Enzyme changes in baker's yeast in drying and long storage. Microbiology, Moscow, 25, 600.

Rothstein, A., Jennings, D. H., Demis, C. \& Bruce, M. (1959). The relationship of fermentation to cell structure in yeast. Biochem. J. 71, 99.

Ting, A. F. \& LuEbBers, R. H. (1957). Viscosity of suspensions of spherical and other isodimensional particles in liquids. Amer. Inst. chem. Engng J. 3, 111.

WHITE, J. (1954). Yeast Technology. London: Chapman and Hall. 